\title{
STRUKTUR KOMUNITAS MANGROVE DI DESA KAHYAPU PULAU ENGGANO
}

\author{
Oleh \\ Nella Tri Agustini ${ }^{*}$, Zamdial Ta'alidin dan Dewi Purnama \\ Program Studi Ilmu Kelautan Fakultas Pertanian Universitas Bengkulu, Bengkulu \\ Email: nellatriagustini@ymail.com \\ Received February 2016, Accepted March 2016
}

\begin{abstract}
ABSTRAK
Metode Penelitian yang dilakukan adalah dengan metode survei melalui observasi langsung di lapangan dan wawancara masyarakat. Data vegetasi mangrove diambil dari tiap transek menggunakan metode transek kuadrat berukuran $10 \mathrm{~m} \times 10 \mathrm{~m}$ (kategori pohon), $5 \mathrm{~m} \times 5 \mathrm{~m}$ (kategori anakan) dan $2 \mathrm{~m} \times$ $2 \mathrm{~m}$ (kategori semai). Hasil penelitian ditemukan sebanyak 8 (delapan) spesies mangrove sejati dan 8 (delapan) spesies mangrove asosiasi. Kerapatan tingkat pohon keseluruhan tergolong jarang, sedangkan tingkat anakan dan semai tergolong rapat. Persen penutupan mangrove tergolong tinggi sehingga termasuk dalam kategori baik. Frekuensi jenis tertinggi untuk tingkat pohon, anakan dan semai yaitu Bruguiera gymnorrhiza, Rhizopora apiculata dan Xylocarpus granatum. Hal ini menunjukkan bahwa keberadaan ketiga jenis ini hampir dapat ditemukan di setiap petak/plot pengamatan pada setiap stasiun penelitian. Indeks Nilai Penting (INP) Mangrove yang didapatkan tergolong sedang, hal ini menunjukkan bahwa mangrove di Desa Kahyapu memiliki peranan yang cukup penting bagi lingkungan pesisir. Nilai indeks dominansi tergolong rendah dan nilai indeks keanekaragaman yang didapatkan tergolong sedang. Hal ini menunjukkan bahwa tidak terdapat jenis yang mendominasi jenis lainnya pada ekosistem mangrove di Desa Kahyapu atau komunitas berada dalam kondisi stabil.
\end{abstract}

Kata kunci : Kahyapu, vegetasi, mangrove

\section{ABSTRACT}

The research method is a survey method through direct observation in the field and interview people. Mangrove vegetation data were taken from each transect using transect method squares measuring $10 \mathrm{~m} \times 10 \mathrm{~m}$ (category tree), $5 \mathrm{~m} \times 5 \mathrm{~m}$ (category tillers) and $2 \mathrm{~m} \times 2 \mathrm{~m}$ (category seedlings). The study found 8 (eight) species of true mangrove and eight (8) species of mangrove associates. Overall density of tree level relatively infrequently, while the level of saplings and seedlings belong to denser. Closing percent of mangrove is high so included in good category. The highest frequency for level types of trees, saplings and seedlings that Bruguiera gymnorrhiza, Rhizophora apiculata and Xylocarpus granatum. This shows that the existence of these three types almost can be found in each plot / plot observations on each of the research station. Index of important value mangrove included in medium category, it indicates that mangrove in Kahyapu village has an important role for the coastal environment. Index of dominance value is low and index of diversity value included in medium category. This shows that there are no species that dominate other species on mangrove ecosystem in Kahyapu village or community was in stable condition. 
Key words : Kahyapu, vegetation, mangrove

\section{PENDAHULUAN}

Pulau Enggano merupakan salah satu pulau terdepan di Indonesia yang berada di samudera Hindia. Secara geografis, Pulau Enggano terletak pada posisi $05^{\circ} 31^{\prime} 13^{\prime \prime}$ LS dan 102 $16^{\prime} 00^{\prime \prime}$ BT. Berdasarkan administratif, Pulau Enggano merupakan sebuah kecamatan yang termasuk dalam wilayah Kabupaten Bengkulu Utara, Provinsi Bengkulu.

Pulau Enggano memiliki banyak potensi sumberdaya alam yang dapat dikelola, khususnya dalam bidang ekosistem mangrove. Pengembangan potensi ekosistem mangrove ini akan berperan secara langsung terhadap keadaan ekosistem pesisir, dimana mangrove memiliki fungsi penting baik secara fisik, biologi maupun ekonomi untuk masyarakat. Ekosistem mangrove banyak memberikan fungsi ekologis dan menjadi salah satu produsen utama perikanan laut. Ekosistem mangrove juga dapat membantu pengembangan dalam bidang sosial dan ekonomi masyarakat sekitar pantai.

Secara ekologis, Pulau Enggano sebagai pulau kecil mempunyai sumberdaya alam yang dominan berupa berbagai ekosistem di wilayah pesisir baik pantai maupun laut. Menurut Dirjen P3K DKP (2002), jenis-jenis ekosistem yang dapat ditemukan di wilayah pesisir dan mempunyai potensi sumberdaya alam penting antara lain adalah ekosistem hutan mangrove, ekosistem padang lamun, ekosistem terumbu karang, ekosistem estuaria dan sumberdaya ikan.

Keadaan ekosistem mangrove di Pulau Enggano masih tergolong alami, hal ini dikarenakan Pulau Enggano merupakan salah satu pulau terdepan yang masih jarang dijumpai oleh banyak orang. Keadaan wilayah pesisirnya pun masih sangat terjaga dengan baik, sehingga pulau ini sangat potensial untuk dikembangkan khususnya pada wilayah ekosistem mangrove yang banyak memiliki fungsi ekologis terhadap lingkungan. Melihat potensi dan begitu pentingnya ekosistem mangrove serta masih sedikitnya data mengenai ekosistem mangrove di Desa Kahyapu, perlu dilakukan adanya sebuah penelitian tentang strukur komunitas ekosistem mangrove di Desa Kahyapu Pulau Enggano. Penelitian struktur komunitas mangrove ini merupakan salah satu aspek penting untuk mengetahui kondisi suatu ekosistem pesisir dan melihat seberapa besar ekosistem mangrove itu berperan penting terhadap lingkungan khususnya di Desa Kahyapu Pulau Enggano.

Tujuan dari penelitian ini adalah :

1. Mendapatkan nilai kerapatan, frekuensi dan penutupan mangrove.

2. Mendapatkan indeks nilai penting mangrove (INP Mangrove).

3. Mendapatkan nilai indeks dominansi dan indeks keanekaragaman mangrove.

Manfaat dari penelitian ini adalah :

1. Tersedia data mengenai indeks nilai penting mangrove (INP Mangrove).

2. Tersedia data mengenai nilai indeks dominansi dan indeks keanekaragaman mangrove.

3. Digunakan sebagai informasi dasar untuk menilai peranan ekosistem mangrove terhadap lingkungan di Desa Kahyapu.

\section{METODE PENELITIAN}

Penelitian ini telah dilaksanakan di ekosistem mangrove Desa Kahyapu Pulau Enggano Provinsi Bengkulu. Penelitian dilakukan selama 5 (Lima) bulan, yaitu pada bulan September - Januari 2014. 
Peralatan yang dipergunakan dalam penelitian ini yaitu GPS, roll meter, camera digital, gunting, refraktometer, multi-parameter analyser, buku identifikasi mangrove, sedangkan bahan yang dipergunakan dalam penelitian ini yaitu tali rafia, plastik sampel, alat tulis kerja dan komunitas mangrove.

\section{Jenis Data yang Dikumpulkan}

Jenis data yang dikumpulkan terdiri dari 2 macam, yaitu data primer dan data sekunder.

\section{Data Primer}

Pengumpulan data primer dilakukan di lokasi penelitian hutan mangrove. Data primer yang dikumpulkan meliputi 10 (sepuluh) tahapan kegiatan, yaitu (a) Identifikasi ekosistem mangrove, (b) kerapatan jenis, (c) kerapatan jenis relatif, (d) Frekuensi jenis, (e) Frekuensi jenis relatif, (f) Penutupan jenis, (g) Penutupan jenis relatif, (h) indeks nilai penting mangrove, (i) Indeks Dominansi dan (j) Indeks Keanekaragaman.

\section{Data Sekunder}

Data sekunder yang dikumpulkan dalam penelitian ini adalah data tentang kondisi umum Pulau Enggano, khususnya di kawasan ekosistem mangrove serta data penelitian hutan mangrove yang pernah dilakukan. Data tentang kondisi umum Pulau Enggano, meliputi sejarah kawasan, luas dan letak, geologi dan tanah, topografi, potensi sumberdaya manusia.

\section{Metode Kerja \\ Penentuan Stasiun penelitian}

Stasiun penelitian dilakukan pada 3 (tiga) stasiun yang berbeda, dimana pada setiap stasiun terdapat 3 (tiga) garis transek dan pada 1 (satu) garis transek terdapat 3 (tiga) petak (plot) pengambilan sampel. Jalur transek pengamatan dimulai dengan arah tegak lurus dari arah laut ke arah darat sepanjang adanya mangrove, dimana jalur transek yang akan dibuat harus mewakili wilayah kajian dan harus mewakili setiap zonasi hutan mangrove yang terdapat di wilayah kajian. Masing-masing transek dalam sub stasiun penelitian memiliki jarak 100 meter, sedangkan jarak antar stasiun sepanjang 300 meter.

\section{Identifikasi Jenis Mangrove}

Identifikasi jenis mangrove dilakukan langsung di lokasi penelitian, sampel yang diambil seperti bentuk daun, bunga dan buah mangrove. Identifikasi mangrove menggunakan buku panduan pengenalan mangrove karangan Noor, dkk. (2006).

\section{Pengukuran Parameter Lingkungan Mangrove}

Pengukuran parameter kondisi lingkungan ekosistem mangrove meliputi pengambilan data seperti data suhu, salinitas, $\mathrm{pH}$ dan substrat. Pada pengukuran salinitas akan diukur dengan menggunakan alat berupa refraktometer dengan cara meneteskan air yang diambil dari lokasi penelitian mangrove pada refraktometer, kemudian dicatat berapa salinitasnya. Untuk pengukuran suhu diukur dengan menggunakan alat berupa termometer yang nantinya berfungsi untuk mengukur kondisi suhu udara maupun suhu perairan pada lokasi penelitian. Pada pengukuran Derajat keasaman $(\mathrm{pH})$ digunakan alat berupa kertas lakmus dengan cara mencelupkan kertas lakmus tersebut pada lokasi penelitian mangrove. Sedangkan untuk parameter lingkungan mangrove yang terakhir adalah substrat, dimana pengukuran substrat ini dilakukan dengan 
melihat secara visual (langsung) bagaimana keadaan substrat yang ada pada lokasi penelitian mangrove. Pengukuran paramater lingkungan mangrove ini dilakukan pada seluruh stasiun yang ada di lokasi penelitian mangrove.

\section{Analisis Data}

Kerapatan Jenis (Di)

Kerapatan jenis (Di) merupakan jumlah tegakan jenis ke-i dalam suatu unit area (Bengen, 2000). Penentuan kerapatan jenis melalui rumus :

Dimana :

$$
\mathrm{Di}=\frac{n i}{A}
$$

Di : Kerapatan jenis ke-i

$\mathrm{Ni} \quad$ : Jumlah total individu

ke-i

A : Luas total area pengambilan contoh $\left(\mathrm{m}^{2}\right)$

\section{Kerapatan Relatif (RDi)}

Kerapatan relatif ( $\mathrm{RDi}$ ) merupakan jumlah perbandingan antara jumlah jenis tegakan jenis ke-1 dengan total tegakan seluruh jenis (Bengen, 2000). Penentuan kerapatan Relatif (RDi) menggunakan rumus :

Dimana :

$$
\mathrm{RDi}=\left[\frac{n i}{\sum n}\right] \times 100
$$

$$
\begin{array}{ll}
\mathrm{RDi} & : \text { Kerapatan Relatif } \\
\mathrm{ni} & : \text { Jumlah total } \\
\sum n & : \text { Total tegakan seluruh } \\
& \text { jenis }
\end{array}
$$

\section{Frekuensi Jenis (Fi)}

Frekuensi jenis ( $\mathrm{Fi}$ ) yaitu peluang ditemukan suatu jenis ke-i dalam semua petak contoh dibanding dengan jumlah total petak contoh yang dibuat (Bengen, 2000), untuk menghitung frekuensi jenis (Fi) digunakan rumus :

$$
\mathrm{Fi}=\frac{p i}{\sum f}
$$

Dimana :

$$
\begin{array}{ll}
\mathrm{Fi} & : \text { Frekuensi jenis ke-i } \\
\mathrm{Pi} & \begin{array}{l}
: \text { Jumlah petak contoh } \\
\text { dimana ditemukan jenis } \\
\text { ke-i }
\end{array} \\
\sum F \quad \begin{array}{l}
\text { : Jumlah total petak } \\
\text { contoh yang dibuat (3 } \\
\text { plot). }
\end{array}
\end{array}
$$

\section{Frekuensi Relatif (RFi)}

Frekuensi relatif (RFi) adalah perbandingan antara frekuensi jenis ke-i dengan jumlah frekuensi seluruh jenis (Bengen, 2000). Untuk menghitung frekuensi relatif menggunakan rumus :

$$
\mathrm{RFi}=\left[\frac{F i}{\sum F}\right] \times 100
$$


Dimana :

$\mathrm{RFi} \quad$ :Frekuensi relatif jenis

$\mathrm{Fi} \quad$ : Frekuensi jenis ke-i

$\sum F \quad$ : Jumlah total petak contoh yang dibuat $(3$ plot).

\section{Penutupan jenis (Ci)}

Penutupan jenis $(\mathrm{Ci})$ adalah luas penutupan jenis ke-i dalam suatu unit area tertentu (Bengen, 2000). Untuk menghitung penutupan jenis menggunakan rumus :

Dimana :

$$
\mathbf{C i}=\frac{\sum B A}{A}
$$

$\mathrm{Ci} \quad$ : Penutupan jenis

$\sum B A \quad: \pi \mathrm{d}^{2} / 4$

$(\mathrm{d}=$ diameter batang

setinggi dada

A : Luas total area

(d=keliling/ $\boldsymbol{\pi}), \boldsymbol{\pi}=3,14$ )

pengambilan contoh $\left(\mathrm{m}^{2}\right)$

\section{Penutupan Relatif (RCi)}

Penutupan relatif $(\mathrm{RCi})$ yaitu perbandingan antara penutupan jenis ke-i dengan luas total penutupan untuk seluruh jenis (Bengen, 2000). Untuk menghitung $\mathrm{RCi}$, maka digunakan rumus :

Dimana :

$$
\mathrm{RCi}=\left(\frac{C i}{\sum C}\right) \times 100
$$

$\mathrm{RCi} \quad$ : Penutupan Relatif

$\mathrm{Ci} \quad$ : Penutupan jenis ke-i

C : Penutupan total untuk seluruh jenis

\section{Indeks Nilai Penting (INP)}

Menurut Sofian dkk. (2012), untuk perhitungan indeks nilai penting mangrove menggunakan rumus sebagai berikut:

1. Untuk tingkat pohon menggunakan rumus :

$$
\text { INP = RDi + RFi +RCi }
$$

2. Untuk tingkat Semai dan Pancang menggunakan rumus :

Dimana :

$$
\text { INP = RDi+ RFi }
$$

INP : Indeks Nilai Penting

RDi : Kerapatan Relatif

$\mathrm{RFi}$ : Frekuensi Relatif

$\mathrm{RCi}$ : Penutupan Relatif

\section{Indeks Dominansi}

Menurut Odum (1993) status kondisi komunitas dapat ditentukan dengan menggunakan indeks dominansi.

Dimana :

$$
\mathrm{D}=\sum_{i=1}^{S}\left[\frac{N i}{N}\right]^{2}
$$




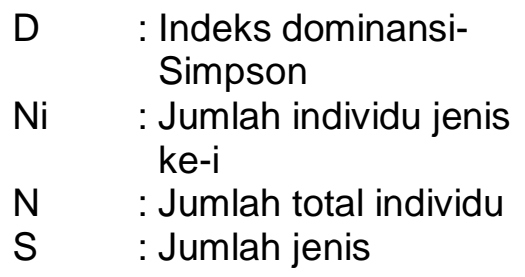

\subsubsection{Indeks Keanekaragaman}

Keanekaragaman ditentukan dengan menggunakan rumus kenekaragaman menurut Shannon-Wiener (1984) dalam Bengen (2000) sebagai berikut :

Dimana :

$$
\mathrm{H}^{\prime}=-\left(\sum \frac{n i}{N} \operatorname{Ln} \frac{n i}{N}\right)
$$

$\mathrm{H}^{\prime} \quad$ : Indeks diversitas jenis

ni : Jumlah individu masing-masing jenis

$\mathrm{N} \quad$ : Jumlah total individu semua jenis

\section{HASIL DAN PEMBAHASAN}

\section{Keadaan Umum Lokasi Penelitian}

Lokasi penelitian berada di Pulau Enggano, tepatnya di Kabupaten Bengkulu Utara sekitar 90 mil laut atau $\pm 166,68 \mathrm{~km}$ dari Provinsi Bengkulu, yaitu di Desa Kahyapu Kecamatan Enggano. Wilayah pesisir di Desa Kahyapu ditumbuhi oleh ekosistem mangrove yang memiliki luas wilayah mangrove sebesar $\pm 250 \mathrm{Ha}$ (Pemda Kabupaten Bengkulu Utara, 2012).

Wilayah pesisir Desa Kahyapu ditumbuhi oleh ekosistem mangrove dengan keadaan yang tergolong alami, hal ini juga dikarenakan Pulau Enggano merupakan salah satu Pulau Kecil terdepan yang masih belum tersentuh oleh banyaknya aktivitas manusia didalamnya. Keberadaan ekosistem mangrove ini memberikan banyak peranan terhadap lingkungan pesisir, antara lain sebagai pelindung pantai dan mampu memberikan nuansa alami dan hijau di sepanjang pesisir pantai Desa Kahyapu.

\section{Komposisi Jenis Mangrove}

Komposisi vegetasi mangrove yang ditemukan di Desa Kahyapu sebanyak 16 (enam belas) jenis, 8 (delapan) jenis mangrove sejati yaitu jenis Acrostichum speciosum, Avicennia lanata, Bruguiera gymnorrhiza, Ceriops tagal, Lumnitzera littorea, Rhizopora apiculata, Sonneratia alba,Xylocarpus granatum dan 8 (delapan) jenis tumbuhan mangrove asosiasi yaitu jenis Barringtonia asiatica, Hibiscus tiliaceus L, Ipomea pes-caprae, Morinda citrifolia, Nypa fruticans, Pandanus tectorius, Pandanus odoratissimus L.f. dan Thespesia populnea.

Jenis mangrove sejati paling banyak ditemukan pada stasiun II. Banyaknya mangrove sejati pada stasiun ini, diduga karena kondisi lingkungan baik substrat maupun salinitas masih bisa ditoleransi oleh berbagai jenis tumbuhan mangrove. Sehingga stasiun ini memiliki kondisi mangrove yang heterogen jika dibandingkan dengan stasiun lainnya yang memiliki kondisi mangrove cenderung homogen, dimana terdapat beberapa jenis mangrove yang lebih banyak ditemukan sehingga keberadaan jenis lain menjadi lebih sedikit.

Jenis mangrove yang paling umum ditemukan pada setiap stasiun penelitian yaitu Bruguiera gymnorrhiza, Rhizopora apiculata, Xylocarpus 
granatum dan Sonneratia alba. Menurut Sofian dkk. (2010) jenis ini memiliki keunggulan dalam menyesuaikan diri dengan kondisi lingkungan. Untuk jenis Acrostichum speciosum hanya ditemukan di stasiun III, stasiun ini memiliki kondisi substrat pasir berlumpur dengan salinitas yang tergolong tinggi. Menurut Noor dkk. (2006) jenis Acrostichum speciosum hanya dapat tumbuh pada daerah mangrove terbuka sebagai individu yang terpisah atau dalam kelompok kecil, juga tumbuh pada daerah yang lebih berpasir dan berkarang atau tergenang oleh air laut dengan salinitas yang sama dengan air laut.

\section{Kerapatan Jenis}

Kerapatan jenis tumbuhan mangrove yang diteliti terdiri dari beberapa tingkatan yaitu tingkatan pohon, anakan dan semai. Dari keseluruhan stasiun penelitian, nilai kerapatan jenis mangrove tertinggi pada tingkat pohon yaitu Bruguiera gymnorrhiza sebanyak 489 pohon/ha (Stasiun I), Xylocarpus granatum sebanyak 400 pohon/ha (Stasiun II) dan Rhizopora apiculata sebanyak 633 pohon/ha (Stasiun III) dan 522 pohon/ha (Stasiun IV). Pada stasiun I, II, dan III nilai kerapatan jenis terkecil yaitu Ceriops tagal, Lumnitzera littorea, Sonneratia alba, Ipomea pes-caprae, Hibiscus tiliaceus $L$ dan Xylocarpus granatum masingmasing sebanyak 11 pohon/ha, pada stasiun IV nilai kerapatan jenis terkecil yaitu Morinda citrifolia sebanyak 22 pohon/ha.

Nilai kerapatan jenis tertinggi tingkat anakan yaitu Bruguiera gymnorrhiza sebanyak 1289 pohon/ha (Stasiun I), Xylocarpus granatum sebanyak 356 pohon/ha (Stasiun II) dan Rhizopora apiculata sebanyak 1511 pohon/ha (Stasiun III) dan 756 pohon/ha (Stasiun IV). Pada stasiun I, nilai kerapatan jenis terkecil yaitu Lumnitzera littorea dan Rhizopora apiculata masing-masing sebanyak 89 pohon/ha, stasiun II yaitu Barringtonia asiatica sebanyak 44 pohon/ha, stasiun III yaitu Avicennia lanata sebanyak 89 pohon/ha dan stasiun IV yaitu Hibiscus tiliaceus $L$ sebanyak 133 pohon/ha.

Pada tingkat pohon dan anakan, jenis Bruguiera gymnorrhiza memiliki nilai kerapatan jenis tertinggi berturut-turut pada stasiun I, IV, III dan II. Nilai kerapatan jenis Bruguiera pada stasiun I diduga karena kondisi substratnya lebih berlumpur jika dibandingkan dengan stasiun lainnya yang memiliki substrat pasir berlumpur. Menurut Nybakken (1988) Bruguiera berkembang pada sedimen yang lebih berat (tanah liat) pada tingkat air pasang-purnama yang tinggi. Nilai kerapatan jenis tertinggi untuk Xylocarpus granatum yaitu pada stasiun II selanjutnya pada stasiun IV dan III. Tingginya nilai kerapatan jenis Xylocarpus pada stasiun II diduga karena kondisi salinitasnya lebih rendah jika dibandingkan dengan stasiun lainnya yang memiliki salinitas yang cukup tinggi. Menurut Noor dkk. (2006) jenis Xylocarpus granatum dapat tumbuh di sepanjang pinggiran sungai dan lingkungan payau lainnya yang tidak terlalu asin.

Nilai kerapatan jenis tertinggi untuk Rhizopora apiculata yaitu pada stasiun III dan IV selanjutnya pada stasiun I dan II. Tingginya nilai kerapatan jenis Rhizopora pada stasiun II diduga karena kondisi substratnya lumpur berpasir dan selalu tergenang pada saat pasang normal. Jika dibandingkan dengan stasiun lainnya yang memiliki kondisi substrat berlumpur dan salinitas yang lebih rendah.

Menurut Nybakken (1988) zona Rhizopora terletak pada tepi yang menghadap ke arah laut. Selanjutnya Watson (1928) dalam Ghufran (2012) menambahkan bahwa zona Rhizopora terletak pada daerah genangan pada saat pasang normal. Untuk jenis Ceriops tagal, Lumnitzera littorea, Sonneratia alba, Barringtonia asiatica, Hibiscus tiliaceus L, Ipomea pes-caprae, Morinda citrifolia, Nypa fruticans, Pandanus tectorius, Pandanus odoratissimus dan Thespesia 
populnea ditemukan hampir sama di setiap stasiun yaitu berkisar 11 - 167 pohon/ha.

Dari keseluruhan stasiun penelitian, nilai kerapatan jenis mangrove tertinggi pada tingkat semai yaitu Rhizopora apiculata sebanyak 9444 individu/ha (Stasiun I), 4722 individu/ha (Stasiun II), 8333 individu/ha (Stasiun III) dan 3611 individu/ha (Stasiun IV). Pada stasiun II, III, dan IV nilai kerapatan jenis terkecil yaitu Lumnitzera littorea (Stasiun II), Xylocarpus granatum (Stasiun III) dan Bruguiera gymnorrhiza sebanyak 22 individu/ha (Stasiun IV).

Nilai kerapatan jenis tertinggi untuk tingkat semai yaitu Rhizopora apiculata pada stasiun I selanjutnya pada stasiun III, II dan IV. Tingginya nilai kerapatan jenis Rhizopora pada stasiun I diduga karena adanya nilai kerapatan jenis tingkat pohon yang lebih jarang. Stasiun I memiliki kondisi substrat berlumpur jika dibandingkan dengan stasiun lainnya yang memiliki kondisi substrat lumpur berpasir dengan kerapatan jenis pohon yang relatif lebih besar.

Menurut Nybakken (1988) jenis mangrove tertentu (Rhizopora, Bruguiera) yang berkembang sendiri pada perairan lautan mempunyai perkembangan bentuk yang khusus pada perkembangan dan penebaran benih. Benih ini ketika masih pada tumbuhan induk, berkecambah dan mulai tumbuh didalam semaian tanpa mengalami istirahat. Hal ini merupakan salah satu faktor tingginya nilai kerapatan jenis pada semai Rhizopora apiculata.

Secara keseluruhan, nilai kerapatan jenis pada tingkat pohon lebih jarang jika dibandingkan dengan anakan dan semai. Salah satu faktor yang mempengaruhi rendahnya nilai kerapatan jenis tingkat pohon adalah besarnya nilai penutupan mangrove dengan diameter berkisar antara $10,19 \mathrm{~cm}-63,69 \mathrm{~cm}$, kondisi ini tidak memungkinkan untuk pertumbuhan pohon mangrove dalam kondisi rapat. Faktor lain yang menyebabkan pertumbuhan mangrove relatif jarang adalah kondisi akar pohon yang tergolong besar sehingga pertumbuhan mangrove tersebut menjadi kurang optimal.

Untuk tingkat anakan dan semai memiliki nilai kerapatan yang baik atau dalam keadaan rapat. Tingginya nilai kerapatan jenis ini juga dipengaruhi oleh nilai penutupan jenis anakan yang masih relatif kecil dengan diameter $<10 \mathrm{~cm}$. Faktor ini yang mendukung pertumbuhan jenis mangrove secara lebih optimal. Menurut Kepmen LH No. 201 Tahun 2004, kriteria nilai kerapatan jenis mangrove pada nilai $\geq 1500$ maka tergolong kategori sangat rapat dan pada nilai $<1000$ maka tergolong dalam kategori jarang.

\section{Frekuensi Jenis}

Frekuensi jenis tumbuhan mangrove yang diteliti terdiri dari beberapa tingkatan yaitu tingkatan pohon, anakan dan semai. Dari keseluruhan stasiun penelitian, nilai frekuensi jenis relatif tertinggi untuk tingkat pohon, anakan dan semai yaitu Bruguiera gymnorrhiza berturut-turut sebesar 22,22 \%, 7,41\%, 16,05 $\%$ (Stasiun I), Xylocarpus granatum sebesar 20,99 \%, 9,88 \% 6,19 \% (Stasiun II) dan Rhizopora apiculata sebanyak 27,16 \%, 11,11\% (tingkat pohon, anakan), $17,28 \%, 6,17 \%$ (tingkat semai, stasiun III dan IV).

Secara keseluruhan, jenis Bruguiera gymnorrhiza, Xylocarpus granatum dan Rhizopora apiculata hampir ditemukan pada setiap plot/petak pengamatan. $\mathrm{Hal}$ ini menunjukkan bahwa ketiga jenis tersebut memiliki penyeberan jenis dan keberadaan yang lebih tinggi jika dibandingkan dengan jenis yang lainnya. Keberadaan jenis Bruguiera, Xylocarpus dan Rhizopora ini ditentukan juga oleh kondisi lingkungan, seperti kondisi substrat dan salinitas yang memungkinkan untuk pertumbuhan mangrove tersebut secara lebih optimal.

Jika dilihat dari lokasi penempatan, ke empat stasiun tersebut berada pada zona air payau (Daerah pantai hingga muara sungai), kondisi tersebut 
mempertegas keberadaan ketiga jenis tersebut yang ditemukan hampir di setiap stasiun penelitian. Menurut Kustanti (2011) spesies jenis Bruguiera gymnorrhiza, Xylocarpus granatum dan Rhizopora apiculata merupakan kelompok vegetasi dominan yang dapat menyesuaikan diri dengan lingkungan.

Untuk jenis Acrostichum speciosum, Avicennia lanata, Ceriops tagal Ipomea pes-caprae, Morinda citrifolia, Nypa fruticans, Pandanus tectorius, Pandanus odoratissimus, Thespesia populnea, Acrostichum speciosum masingmasing penyebaran jenisnya tidak selalu ditemukan pada setiap stasiun penelitian. Hal ini dikarenakan tumbuhan non-mangrove hanya berasosiasi di lingkungan mangrove yang lebih kearah daratan.

\section{Penutupan Jenis}

Dari keseluruhan stasiun penelitian, nilai penutupan jenis mangrove tertinggi yaitu Bruguiera gymnorrhiza sebesar 62,62 \% (Stasiun I), Xylocarpus granatum sebesar 43,59 \% (Stasiun II) dan Rhizopora apiculata sebesar 72,68\% (Stasiun III) dan 46,54 \% (Stasiun IV). Pada stasiun I nilai penutupan jenis terkecil yaitu Ceriops tagal dan Sonneratia alba masing-masing sebesar 36,04 \%, stasiun II yaitu Hibiscus tiliaceus $L$ sebesar 1,78 \% stasiun III yaitu Xylocarpus granatum sebesar $1,59 \%$ dan stasiun IV yaitu Ceriops tagal sebesar 2,22 \%.

Nilai penutupan jenis tertinggi untuk Bruguiera gymnorrhiza yaitu pada stasiun I selanjutnya pada stasiun IV, II dan III. Tingginya nilai penutupan jenis Bruguiera pada stasiun I diduga karena kondisi pohonnya memiliki diameter lebih tinggi jika dibandingkan jenis Ceriops tagal dan Sonneratia alba yang memiliki diameter kecil sehingga nilai penutupan jenisnya lebih rendah. Stasiun I memiliki kondisi substrat berlumpur, sehingga memberikan kondisi yang baik bagi pertumbuhan Bruguiera gymnorrhiza. Menurut Nybakken (1988) pohon-pohon genus Bruguiera berkembang pada sedimen yang lebih berat (tanah liat) pada tingkat air pasang-purnama yang tinggi.

Penutupan jenis tertinggi untuk Xylocarpus granatum yaitu pada stasiun II selanjutnya pada stasiun IV dan III. Nilai penutupan jenis Xylocarpus di stasiun II tergolong jarang. Hal ini dipengaruhi oleh kondisi lingkungan stasiun II yang memiliki kondisi substrat pasir berlumpur dan berada lebih dekat ke arah daratan.

Faktor lain yang mempengaruhi rendahnya nilai penutupan jenis ini adalah adanya kondisi mangrove yang heterogen. Menurut Raymond dkk. (2010) semakin heterogen jenis mangrove dalam suatu komunitas maka peranannya akan terbagi-bagi dan besarnya indeks akan semakin bervariasi.

Nilai penutupan jenis tertinggi untuk Rhizopora apiculata yaitu pada stasiun III selanjutnya pada stasiun IV, I dan II. Tingginya nilai penutupan jenis Rhizopora pada stasiun I diduga karena kondisi pohon Rhizopora memiliki diameter lebih tinggi jika dibandingkan dengan jenis lainnya yang memiliki diameter lebih kecil sehingga nilai penutupan mangrovenya lebih rendah. Stasiun III memiliki kondisi substrat relatif lumpur berpasir dengan keadaan tergenang pada saat pasang normal.

Menurut Nontji (1986), pada tempat yang terlindung dari hempasan ombak, komunitas mangrove terutama diungguli oleh bakau Rhizopora apiculata. Selanjutnya Sofian $d k k$. (2012) menyatakan bahwa kondisi hutan mangrove yang berhadapan langsung dengan laut sehingga mendapatkan pasang surut air laut sangat mendukung jenis tersebut untuk tumbuh.

Nilai penutupan jenis Acrostichum speciosum, Avicennia lanata, Ceriops tagal dan Sonneratia alba hampir sama di setiap stasiun penelitian, yaitu berkisar antara $0,13-3,14 \%$. Hal ini menunjukkan bahwa nilai penutupan jenis yang ada tergolong rendah. 
Dari keseluruhan stasiun penelitian, nilai penutupan jenis mangrove tertinggi yaitu $62,62 \%$ (Stasiun I) dan $72,68 \%$ (Stasiun III). Untuk nilai penutupan jenis terkecil yaitu 43,59 \% (Stasiun II) dan 46,54\% (Stasiun IV) (Gambar 9). Perbedaan yang terjadi di setiap stasiun penelitian dipengaruhi oleh kondisi lingkungan, jumlah tegakan mangrove, hingga daya adaptasi mangrove terhadap lingkungan.

Nilai penutupan jenis tertinggi yaitu berkisar antara 62,62-72,68 \%. Untuk nilai penutupan jenis terkecil berkisar antara 43,59-46,54\%. Menurut KepMen LH No. 201 Tahun 2004 kriteria penutupan jenis pada nilai $>50 \%-<75 \%$ maka tergolong baik (kategori penutupan sedang) dan pada nilai $<50 \%$ maka tergolong buruk (kategori penutupan jarang). Dengan demikian, untuk stasiun dan III termasuk dalam kategori baik dengan nilai > 50\%. Untuk stasiun II dan IV termasuk dalam kategori jarang dengan nilai $<50 \%$.

\section{Indeks Nilai Penting (INP) Mangrove}

Indeks Nilai Penting (INP) mangrove yang didapatkan terdiri dari beberapa tingkatan yaitu tingkatan pohon, anakan dan semai. Data indeks nilai penting (INP) mangrove terlampir pada Lampiran 3. Kisaran indeks nilai penting (INP) mangrove untuk tingkat pohon, anakan dan semai berturut-turut yaitu berkisar antara 2,25-162,50, 47,44-66,67 dan 27,41-81,73.

Pada stasiun I nilai INP tertinggi untuk tingkat pohon, anakan dan semai yaitu Bruguiera gymnorrhiza berturut-turut sebesar 142,36, 47,44 dan 71,60. Untuk INP terkecil yaitu Ceriops tagal dan Sonneratia alba (tingkat pohon), Lumnitzera littorea (tingkat anakan) dan Avicennia lanata (tingkat semai). Hal ini menunjukkan bahwa jenis Bruguiera gymnorrhiza memiliki peranan cukup penting pada lingkungan pesisir.

Pada stasiun II, nilai INP tertinggi untuk tingkat pohon, anakan dan semai yaitu Xylocarpus granatum berturut-turut sebesar 107,27, 48,77 dan 28,41. Untuk INP terkecil yaitu Hibiscus tiliaceus L (tingkat pohon), Bruguiera gymnorrhiza (tingkat anakan), Avicennia lanata, Bruguiera gymnorrhiza, Rhizopora apiculata dan Lumnitzera littorea (tingkat semai). Hal ini menunjukkan bahwa jenis Xylocarpus granatum memiliki peranan cukup penting pada lingkungan pesisir.

Pada stasiun III dan IV, nilai INP tertinggi untuk tingkat pohon, anakan dan semai yaitu Rhizopora apiculata dengan jumlah INP tertinggi pada stasiun III sebesar 162,50 (tingkat pohon), 55,31 (tingkat anakan), dan 81,73 (tingkat semai). Pada stasiun IV jumlah INP tertinggi sebesar 120,06 (tingkat pohon), 66,67 (tingkat anakan), dan 39,51 (tingkat semai). Untuk INP terkecil terdapat pada jenis Morinda citrifolia (tingkat pohon), Hibiscus tiliaceus $L$ (tingkat anakan), dan Bruguiera gymnorrhiza (tingkat semai). Hal ini menunjukkan bahwa jenis Rhizopora apiculata memiliki peranan cukup penting pada lingkungan pesisir.

Dari keseluruhan stasiun penelitian, dijumpai 3 (tiga) jenis vegetasi yang memiliki INP tertinggi dan tersebar baik untuk tingkat pohon, anakan dan semai yaitu Bruguiera gymnorrhiza, Rhizopora apiculata, dan Xylocarpus granatum. Ketiga jenis tersebut berperan cukup penting dalam lingkungan pesisir Desa Kahyapu. Indeks nilai penting (INP) mangrove menunjukkan keterwakilan jenis mangrove yang berperan dalam ekosistem dengan kisaran nilai antara 0-300.

Untuk tingkat pohon mangrove memiliki INP tergolong sedang yaitu berkisar antara 107,27-162,50. Menurut Romadhon (2008), apabila INP berkisar antara 106-204 maka tergolong sedang. Untuk tingkat anakan dan semai memiliki INP tergolong rendah yaitu berkisar antara 47,44-66,67 dan 27,4181,73 . Menurut Sofian $d k k$. (2012), apabila INP $<76,03$ maka tergolong rendah.

Indriyanto (2006) berpendapat bahwa spesies-spesies yang dominan (yang berkuasa) dalam suatu komunitas tumbuhan akan memiliki indeks nilai 
penting yang tinggi, sehingga spesies yang paling dominan akan memiliki indeks nilai penting yang paling besar. Selanjutnya Raymond $d k k$. (2010) menambahkan bahwa jenis yang memperoleh INP tinggi berarti mempunyai nilai kumulatif penguasaan yang lebih besar dan lebih menguasai habitatnya. Jenis ini akan lebih unggul dalam memanfaatkan sumberdaya atau lebih dapat menyesuaikan diri dengan lingkungan setempat.

Hasil indeks nilai penting (INP) mangrove memperlihatkan adanya perbedaan nilai INP dari tiap tingkatan yaitu baik tingkatan pohon, anakan dan semai. Hal ini menggambarkan bahwa pengaruh suatu jenis dalam komunitas mangrove berbeda dari setiap tingkatan. Untuk tingkat pohon memiliki nilai INP tetinggi jika dibandingkan dengan tingkat anakan dan semai, hal ini dipengaruhi oleh nilai penutupan jenis yang lebih besar sehingga menghasilkan INP yang lebih tinggi. Menurut Odum (1993) dalam Raymond dkk. (2010) pengaruh suatu populasi terhadap komunitas dan ekosistem tidak hanya bergantung pada spesies dari organinasi yang terlibat tetapi bergantung juga pada jumlah atau kepadatan populasi.

\section{Indeks Dominansi (C) dan Indeks Keanekaragaman (H')}

Kisaran nilai indeks dominansi $(\mathrm{C})$ pada setiap stasiun penelitian yaitu berkisar antara 0,23-0,42. Nilai indeks dominansi yang didapatkan tergolong rendah, hal ini menunjukkan bahwa tidak terdapat jenis yang mendominasi jenis lainnya atau komunitas berada dalam kondisi stabil. Menurut Odum (1993), jika nilai $0<D \leq 0,5$ maka dominansi rendah. Untuk nilai $D=1$ berarti terdapat jenis yang mendominasi jenis lainnya atau komunitas berada dalam kondisi labil karena terjadi tekanan ekologis. Selanjutnya Indriyanto (2006) menambahkan bahwa apabila indeks dominansi tinggi, maka dominansi (penguasaan) terpusat (terdapat) pada satu spesies. Tetapi apabila nilai indeks dominansi rendah, maka dominansi terpusat (terdapat) pada beberapa spesies.

Kisaran nilai indeks keanekaragaman $\left(\mathrm{H}^{\prime}\right)$ pada setiap stasiun penelitian yaitu berkisar antara 1,53-2,34. Nilai indeks keanekaragaman ( $\left.\mathrm{H}^{\prime}\right)$ yang didapatkan tergolong sedang. Hal ini menunjukkan bahwa komunitas tersebut memiliki kompleksitas sedang karena interaksi spesies yang terjadi di dalam komunitas itu cukup baik.

Menurut Indriyanto (2006) keanekaragaman spesies juga dapat digunakan untuk mengukur stabilitas komunitas, yaitu kemampuan suatu komunitas untuk menjaga dirinya tetap stabil. Berdasarkan kriteria yang dikemukakan oleh Bengen (2000) bahwa secara umum nilai indeks keanekaragaman jenis tumbuhan mangrove yang terdapat di Desa Kahyapu tergolong sedang melimpah dengan nilai $\mathrm{H}^{\prime} 1 \leq \mathrm{H} \leq^{\prime} 3$.

\section{Kondisi Lingkungan Mangrove}

Kondisi lingkungan di setiap stasiun penelitian tergolong baik bagi pertumbuhan mangrove, baik kondisi substrat, suhu, $\mathrm{pH}$, maupun salinitas. Kondisi lingkungan ekosistem mangrove di lokasi penelitian pada tiap stasiun dapat diilihat pada Tabel 5.

Tabel 5. Parameter Lingkungan Ekosistem Mangrove di Desa Kahyapu.

\begin{tabular}{|c|c|c|c|c|c|c|}
\hline \multirow[t]{2}{*}{ No. } & \multirow{2}{*}{$\begin{array}{l}\text { Parameter } \\
\text { Lingkungan }\end{array}$} & \multicolumn{5}{|c|}{ STASIUN } \\
\hline & & $\mathrm{I}$ & II & III & IV & Rata-Rata \\
\hline 1. & Suhu & $22,5^{\circ} \mathrm{C}$ & $20,4^{\circ} \mathrm{C}$ & $29,5^{\circ} \mathrm{C}$ & $24,7^{\circ} \mathrm{C}$ & $24,3^{\circ} \mathrm{C}$ \\
\hline 2. & Salinitas & $20 \%$ & $9,7 \%$ & $23 \%$ & $21 \%$ & $18,4 \%$ \\
\hline 3. & $\mathrm{pH}$ & 6,0 & 6,27 & 6,51 & 6,23 & 6,25 \\
\hline
\end{tabular}




\begin{tabular}{cccccc}
\hline 4. Substrat & $\begin{array}{c}\text { Berlumpu } \\
r\end{array}$ & $\begin{array}{c}\text { Pasir } \\
\text { Berlumpu } \\
r\end{array}$ & $\begin{array}{c}\text { Pasir } \\
\text { Berlumpur }\end{array}$ & $\begin{array}{c}\text { Pasir } \\
\text { Berlumpur }\end{array}$ & $\begin{array}{c}\text { Pasir } \\
\text { Berlumpur }\end{array}$ \\
\hline
\end{tabular}

Sumber: Hasil pengukuran langsung data primer (2013)

\section{Kesimpulan}

\section{KESIMPULAN DAN SARAN}

Berdasarkan hasil penelitian yang telah dilakukan terhadap struktur komunitas ekosistem mangrove di Desa Kahyapu masih tergolong alami. Komposisi jenis mangrove yang ditemukan sebanyak 16 (enam belas) jenis, 8 (delapan) jenis mangrove sejati yaitu jenis Acrostichum speciosum, Avicennia lanata, Bruguiera gymnorrhiza, Ceriops tagal, Lumnitzera littorea, Rhizopora apiculata, Sonneratia alba, Xylocarpus granatum dan 8 (delapan) jenis tumbuhan mangrove asosiasi yaitu jenis Barringtonia asiatica, Hibiscus tiliaceus $L$, Ipomea pes-caprae, Morinda citrifolia, Nypa fruticans, Pandanus tectorius, Pandanus odoratissimus L.f. dan Thespesia populnea.

Ekosistem mangrove di Desa Kahyapu memiliki nilai kerapatan jenis tingkat pohon dengan kategori jarang, sedangkan nilai kerapatan jenis tingkat anakan dan semai dengan kategori rapat. Nilai frekuensi jenis tertinggi untuk tingkat pohon, anakan dan semai yaitu Bruguiera gymnorrhiza, Rhizopora apiculata dan Xylocarpus granatum. Hal ini menunjukkan bahwa keberadaan ketiga jenis ini hampir dapat ditemukan di setiap petak/plot pengamatan pada setiap stasiun. Persen penutupan tumbuhan mangrove di Desa Kahyapu tergolong tinggi sehingga temasuk dalam kategori baik.

Indeks Nilai Penting (INP) mangrove menunjukkan peran penting mangrove Desa Kahyapu dalam menjaga lingkungan pesisir tergolong tinggi untuk tingkat pohon berkisar antara 107,27-162,50. Nilai indeks dominansi pada ekosistem mangrove di Desa Kahyapu tergolong rendah dan nilai indeks keanekaragaman yang didapatkan tergolong sedang. Hal ini menunjukkan bahwa tidak terdapat jenis yang mendominasi jenis lainnya pada ekosistem mangrove di Desa Kahyapu atau komunitas berada dalam kondisi stabil.

Dari hasil pengukuran nilai parameter lingkungan seperti suhu, salinitas, $\mathrm{pH}$ dan substrat didapatkan nilai rata-rata berturut-turut yaitu suhu $24,3{ }^{\circ} \mathrm{C}$, salinitas 18,4\%o, derajat keasaman $(\mathrm{pH}) 6,25$, dan kondisi substrat tergolong lumpur berpasir. Dari kategori nilai diatas menunjukkan bahwa kondisi lingkungan yang ada di Desa Kahyapu tergolong baik untuk pertumbuhan ekosistem mangrove.

\section{Saran}

Mengingat pentingnya fungsi dan peranan dari ekosistem mangrove, perlu adanya penguatan pemahaman semua pihak untuk terus menjaga keberlangsungan ekosistem mangrove di Desa Kahyapu. Harus adanya penguatan penegakan peraturan tentang pemanfaatan dan pengelolaan mangrove yang dikelola secara terpadu oleh berbagai sektor untuk menghindari konflik dan memperoleh sinergitas antar sektor.

Harus adanya penguatan penegakan peraturan tentang pemanfaatan dan pengelolaan mangrove secara berkelanjutan. Dengan demikian pemanfaatan ekosistem mangrove dapat dikelola untuk tujuan jangka panjang. Mengingat pentingnya fungsi dan peranan dari ekosistem mangrove, perlu adanya penguatan pemahaman semua pihak untuk terus menjaga keberlangsungan ekosistem mangrove di Desa Kahyapu. Perlu dilakukan sosialisasi kepada masyarakat Pulau Enggano tentang ekosistem mangrove, mengingat ekosistem 
ini memiliki fungsi penting baik secara biologi, fisik dan ekonomi di Desa Kahyapu.

\section{DAFTAR PUSTAKA}

Bengen, D.G. 2000. Pedoman Teknis Pengenalan dan Pengelolaan Ekosistem Mangrove, Pusat Kajian Sumberdaya Pesisir dan Lautan. IPB. Bogor.

Dirjen P3K DKP. 2002. Modul Sosialisasi dan Orientasi Pemanfaatan Ruang Laut, Pesisir dan Pulau-Pulau kecil. Direktorat Tata Ruang Laut dan Pesisir dan Pulau-Pulau Kecil, DKP RI, Jakarta. 96 p.

Ghufran, M dan Kordi, H. 2012. Ekosistem Mangrove: Potensi, Fungsi dan Pengelolaan. PT. Rineka Cipta, Jakarta.

Indriyanto. 2006. Ekologi Hutan. PT. Bumi Aksara, Jakarta.

KepMen LH. 2004. Kriteria Baku Dan Pedoman Penentuan Kerusakan Mangrove. Keputusan Menteri Negara Lingkungan Hidup, Nomor 201.

Nontji, A. 1986. Laut Nusantara. Djambatan, Jakarta.

Noor,Y., Khazali, M dan Suryadiputra. 2006. Panduan Pengenalan Mangrove di Indonesia. Oxfam Novib, Bogor.

Nybakken,W.J. 1988. Biologi Laut: Suatu Pendekatan Ekologis. PT. Gramedia, Jakarta.

Nybaken, J.W. 1992. Biologi Laut Suatu Pendekatan Ekologis. Diterjemahkan oleh Eidman, Koesoebiono, D.G. Bengen, M. Hutomo dan S Sukarjo. Gramedia. Jakarta. 459 hal.

Odum, E.P.1993. Dasar-dasar Ekologi. Terjemahan Tjahjono Samingan. Yogyakarta: Gadjah Mada University Press.

Raymond, G., Harahap, N dan Soenarno. 2010. Pengelolaan Hutan Mangrove Berbasis Masyarakat Di Kecamatan Gending, Probolinggo. Agritek, Vol.18 No.2 April 2010 (185-200).

Romadhon. 2008. Kajian Ekologi Melalui Inventarisasi dan Nilai Indeks Penting (INP) Mangrove Terhadap Perlindungan Lingkungan Kepulauan Kangean. Embryo, Vol.5 No.1 (82-97)

Sofian, A., Harahab, N dan Marsoedi. 2012. Kondisi Dan Manfaat Langsung Ekosistem Mangrove Desa Penunggul Kecamatan Nguling Kabupaten Pasuruan. El-Hayah. Vol. 2, No. 2 Maret 2012 (56-63). 